\title{
Regional Brain Glucose Utilization in Adenylosuccinase-Deficient Patients Measured by Positron Emission Tomography
}

\author{
A. G. DE VOLDER, J. JAEKEN, ${ }^{1}$ G. VAN DEN BERGHE, ${ }^{2}$ A. BOL, CH. MICHEL, M. COGNEAU, \\ AND A. M. GOFFINET
}

Positron Tomography Laboratory, University of Louvain, B-1348 Louvain-la-Neuve, Belgium

\begin{abstract}
Regional brain glucose utilization was investigated by positron emission tomography with fluorodeoxyglucose in three children with adenylosuccinase deficiency. A consistent pattern was found in the three patients, namely a marked decrease of fluorodeoxyglucose uptake in all gray structures, with the exception of the cerebellum, which was minimally affected. Anomalies predominated in the cerebral cortex, particularly in the anterior regions; they were less pronounced in thalamus and basal ganglia. The observations suggest that positron emission tomography may be a useful tool for the localization of the deleterious effects of metabolic diseases and for the investigation of their pathophysiologic mechanisms. (Pediatr Res 24: 238-242, 1988)
\end{abstract}

\section{Abbreviations}
AICAR, aminoimidazole carboxamide ribotide
FDG, fluorodeoxyglucose
FWHM, full-width at half maximum
HPRT, hypoxanthine-guanine phosphoribosyl transferase
PET, positron emission tomography
PKU, phenylketonuria
S-adenosine, succinyl adenosine
SAICAR, succinylaminoimidazole carboxamide ribotide
S-AMP, adenylosuccinate

Adenylosuccinase deficiency is a recently described inborn error of metabolism, the first reported enzyme deficiency involving the de novo synthesis of purine nucleotides (1). Adenylosuccinase (adenylosuccinate lyase: E.C. 4.3.2.2.) catalyses two steps in purine synthesis (Fig. 1): the conversion of SAICAR into AICAR, and that of S-AMP into AMP. Affected patients display psychomotor retardation accompanied by autistic features. The enzyme defect is manifested by the presence in cerebrospinal fluid, plasma, and urine of two normally undetectable compounds, SAICAriboside and succinyladenosine (S-adenosine). These are the products of the dephosphorylation, by cytosolic $5^{\prime}$-nucleotidase (2), of the two substrates of adenylosuccinase. As in other inborn errors of metabolism affecting psychomotor

Received January 18, 1988; accepted April 18, 1988

Correspondence and reprint requests Dr. A. G. De Volder, Positron Tomography Laboratory, Chemin du Cyclotron, 2, B-1348 Louvain-la-Neuve, Belgium.

Supported by FRSM Grants 3.4540 .81 and 3.4540 .84 .

${ }_{1}^{1}$ Present address: Department of Pediatrics, University Hospital Gasthuisberg, B-3000 Leuven, Belgium.

${ }^{2}$ Present address: Laboratory of Physiological Chemistry, International Institute of Cellular and Molecular Pathology, B-1200 Brussels, Belgium. development, the relationship between the enzyme defect and the neurologic dysfunction is poorly understood.

Our study was undertaken as an attempt to gain insight into the pathophysiology of the disease and to localize the regions of the brain where the enzyme defect exerts its deleterious effects. Inasmuch as glucose, with oxygen, is the main substrate of the brain at all ages, regional uptake of a glucose analog in this tissue provides an index of local neural function (3).

\section{PATIENTS}

The three adenylosuccinase-deficient patients A, B and C, were described previously (1). At the time of study, they were aged $3.5,7$, and $5 \mathrm{yr}$, respectively. The cardinal symptoms were a profound psychomotor retardation (developmental age between 5 and 7 months with a slightly better gross motor performance), accompanied by autistic traits. Since their original description, patients $\mathrm{B}$ and $\mathrm{C}$ have developed a progressively more pronounced muscular atrophy and growth failure, which became apparent from the age of about $2 \mathrm{yr}$. Moreover, seizures have appeared between 4 and $5 \mathrm{yr}$ of age (4). X-ray CT-scan of the brain revealed hypoplasia of the cerebellar vermis. Control studies were performed in 10 normal adult volunteers aged 20-22 yr and in three children with normal IQ and minimal neurologic symptoms (aged 5, 14, and $15 \mathrm{yr}$ ). Clinical diagnoses in those cases were, respectively, hysteria (retrospective diagnosis), mild behavioral anomalies of unknown origin, and well-equilibrated temporal epilepsy. The results were also compared to those obtained in a 17 -yr-old girl with poorly equilibrated PKU, in whom blood phenylalanine levels had been consistently higher than $20 \mathrm{mg} / 100 \mathrm{ml}$ for several years and whose IQ was $60-70$. Informed consent was obtained from the parents in all cases. The investigations were approved by the University Medical Ethics Committee.

\section{POSITRON EMISSION TOMOGRAPHY}

Positron emission density data were collected with an ECAT III (CTI) one-ring tomograph, with characteristics and performances as described (5). Measurements were performed with a stationary ring, at an in-plane resolution of $9 \mathrm{~mm}$ FWHM. The collimator aperture was set at $30 \mathrm{~mm}$, resulting in a slice thickness of $15 \mathrm{~mm}$ FWHM. Images were corrected for attenuation by using an ellipse for approximation of the head's contour, with a uniform attenuation coefficient $(\mu)$ of 0.09 . Tests on adult subjects showed that this procedure results in a maximal $5 \%$ error in the attenuation correction. When an arterial input function was available, images of emission density were transformed into images of glucose utilization by using the operational equations of Phelps et al. (6), with the following constants: $\mathrm{k} 1=$ $0.092 ; \mathrm{k} 2=0.14 ; \mathrm{k} 3=0.075 ; \mathrm{k} 4=0.0056 ;$ lumped constant $=$ 


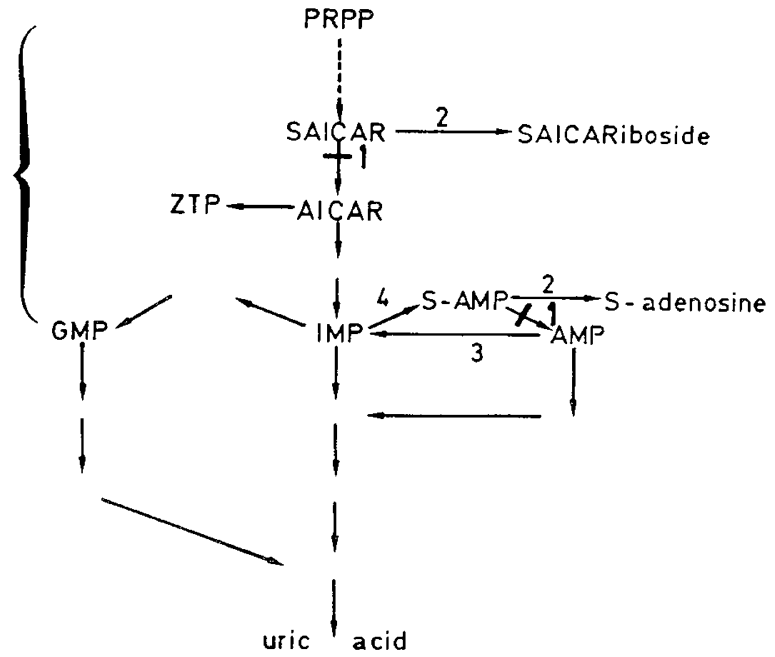

Fig. 1. Simplified pathway of purine metabolism. $P R P P$, phosphoribosyl pyrophosphate; ZTP, AICAR triphosphate; IMP, inosine monophosphate. Only the reactions that are mentioned in the "Discussion" are shown: 1 , adenylosuccinase; 2, cytosolic 5 ' nucleotidase; 3, AMP deaminase; 4 , adenylosuccinate synthetase; vertical bar, pathway of de novo purine synthesis.

0.42. Regions of interest were defined on the images by reference to common neuroanatomical hallmarks and to CT scans.

The three subjects were drug free for several days and fasted for at least $2 \mathrm{~h}$ before the study. No premedication was given. A sterile, isotonic solution of FDG $(100-150 \mu \mathrm{Ci} / \mathrm{kg}$ body weight) was injected as a bolus in $30 \mathrm{~s}$ via a Teflon catheter inserted into a forearm vein. For measurement of the arterial input function, serial blood samples were taken from the radial artery, via a 24gauge catheter (Medicut) placed under local anesthesia with bupivacain. Because of poor patient cooperation, arterial blood samples could not be obtained in patients A and C. Plasma samples were counted in a Berthold $\gamma$-spectrometer calibrated against the PET tomograph. Plasma glucose was measured with a Beckman glucose analyzer.

After the period of maximal FDG uptake (30-45 min), flunitrazepam (Rohypnol) was administered intravenously to allow good positioning of the patient's head. Tomographic slices were oriented parallel to the canthomeatal line. Sequences of six to eight images were collected at $10-\mathrm{mm}$ intervals, starting from the level of the cerebellum. With a slice thickness of $15 \mathrm{~mm}$ FWHM, this method allows some overlap between adjacent sections.

\section{RESULTS}

Images of FDG uptake in patient B with adenylosuccinase deficiency, in a control child, and in the poorly equilibrated PKU patient are shown in Figure 2. Their comparison reveals a profound decrease in FDG uptake in all cortical areas of the adenylosuccinase deficient patient (Fig. 2A). The anomalies clearly predominated in the frontal cortical areas and decreased progressively toward the posterior cortical fields. FDG accumulation was relatively well preserved in the posterior cortical regions, particularly in the visual cortex (areas 17 and 18). It should nevertheless be noted that, owing to poor collaboration of the subjects, the studies were performed with the eyes open. Uptake in the thalamus and basal ganglia was also decreased, albeit to a lesser extent than in the frontal cortex. The cerebellum was minimally affected. Similar images were obtained in patients $A$ and $C$ (not illustrated). The uptake map of the PKU patient (Fig. 2C) disclosed some alterations in the frontal cortex, with relative sparing of other cortical areas, basal ganglia, thalamus, and cerebellum. The decrease in FDG uptake in the frontal areas was, however, much less prominent than in the adenylosuccinase-deficient patient.

Inasmuch as cerebellar FDG uptake was in the normal range in the quantitative study of the most affected subject (patient B in Table 2), and because all three patients displayed profuse cortical alterations, the more common procedure of normalization to a mean gray value (3) was replaced by normalization to the cerebellum as in other cases of cortical pathology (7). These "relative metabolic indexes" are given in Table 1. In the three adenylosuccinase-deficient patients, they were decreased by $30-$ $40 \%$ in all areas when compared to the control children $(p<$ 0.05 with Student's $t$ test, for all regions). The alterations were less marked when compared with the adult volunteers. In most regions, the pattern of metabolic alterations was similar in the three adenylosuccinase-deficient patients. However, patient B, the oldest, displayed a more pronounced deficit in FDG uptake in the frontal and in the frontomesial cortex. In the patient with poorly equilibrated PKU, the anomalies of the normalized metabolic indexes were most pronounced at the level of the cortex, particularly in the frontal lobes, whereas basal ganglia were unaffected. Although the anomalies were clearly not as severe, their distribution was reminiscent of that found in the children with adenylosuccinase deficiency.

Table 2 shows the glucose utilization rates (in $\mu \mathrm{mol} / \mathrm{min} / 100$ $\mathrm{g}$ of tissue) in the various brain regions of patient $\mathrm{B}$, as compared to control children, adult volunteers, and the PKU patient. In accordance with the data of Table 1 , glucose utilization in all forebrain areas of the adenylosuccinase-deficient patient was reduced by more than $50 \%$ as compared to the control children and by at least $40 \%$ as compared to adult volunteers. Metabolic rates for the cerebellum were within normal values defined in the young adult subjects, although slightly lower ( -1 SD) than those found in the control children. The glucose utilization rates, as with the relative metabolic indexes, were much less decreased in the child with PKU than in the adenylosuccinase-deficient patient.

\section{DISCUSSION}

This study reveals consistent perturbations of cerebral FDG uptake in three children with adenylosuccinase deficiency. The alterations display a regional distribution. They predominate in rostral cortical fields and decrease progressively toward posterior cortical areas. The functional disturbances occur in the absence of structural changes as defined on x-ray $\mathrm{CT}$ scans, which are normal in the three patients, with the exception of some hypotrophy of the cerebellar vermis. In this respect, it is remarkable that cerebellar glucose metabolism is surprisingly well preserved. The study provides information about the repercussions of the enzyme defect on regional cerebral function.

The observation that the concentration of the two succinylpurines, SAICAriboside and S-adenosine, is 10- to 20-fold higher in the cerebrospinal fluid of the patients than in their plasma (1), provides a strong indication that adenylosuccinase is deficient in their brain. However, no further information about the enzyme defect in this tissue is available. The predominance of the alterations of the uptake of FDG in the anterior regions of the cerebral cortex suggests that, either the deficiency of adenylosuccinase is exclusively or predominantly located in these regions, or that the consequences of the enzyme defect are most pronounced therein.

Several mechanisms have been proposed $(2,4)$ that could account for the symptoms of adenylosuccinase deficiency: 1 ) impairment of the synthesis of the metabolites that are normally formed distally to the two adenylosuccinase-catalyzed reactions, namely the adenine and guanine nucleotides and, hypothetically, AICAR triphosphate, a newly discovered derivative of AICAR, often abbreviated ZTP; 2 ) intracellular accumulation, up to toxic concentrations, of SAICAR and adenylosuccinate, the substrates of adenylosuccinase; 3) impairment of the purine nucleotide cycle (8), composed of the enzymes adenylosuccinate synthetase, 
DE VOLDER $E T A L$.
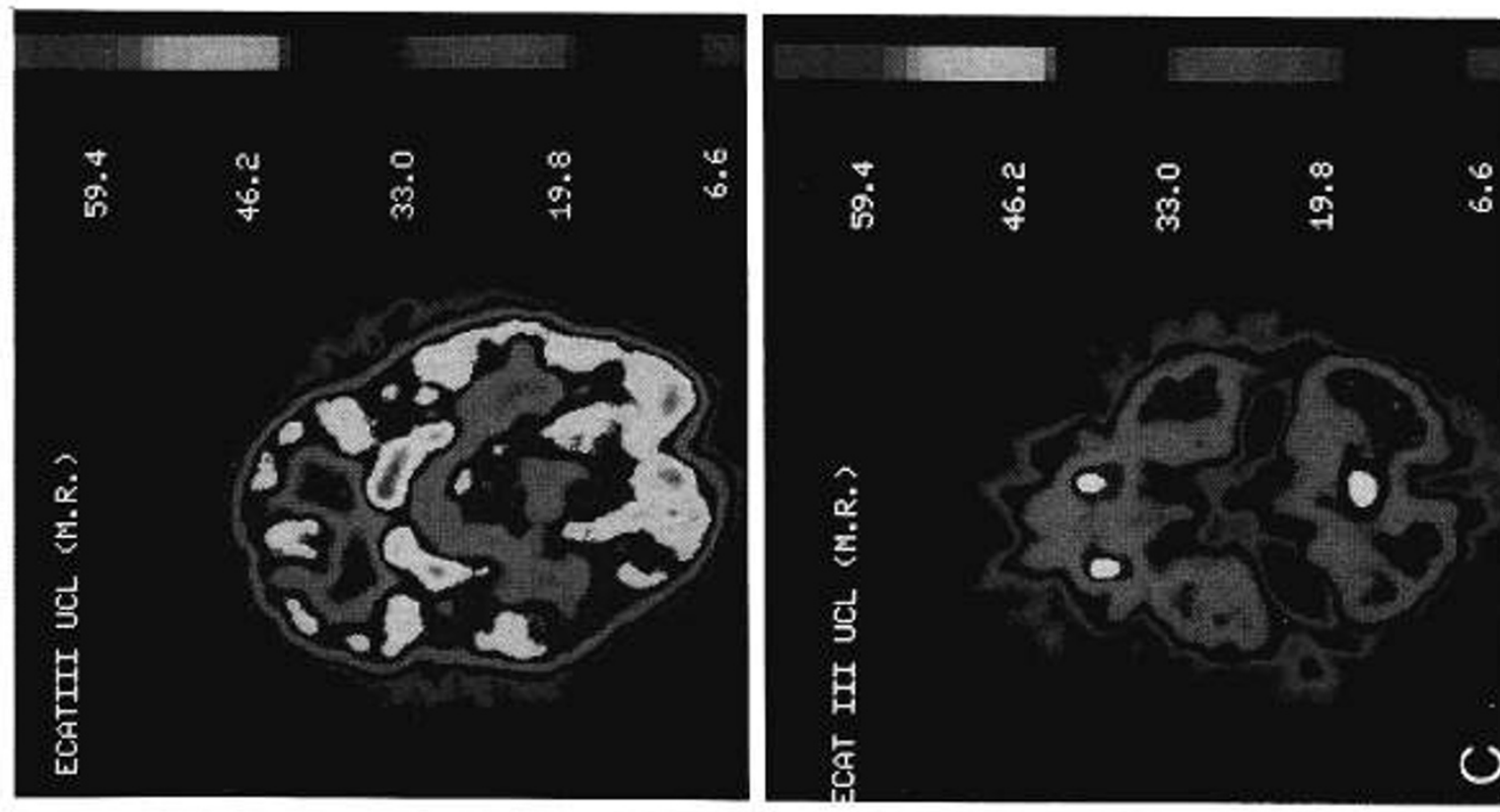

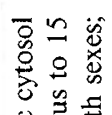

总总

究客客

突 है

뭉ㅇㅇㅇ

范 हี है

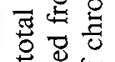

4 运

空

诺

害部

त है

可思

这

)

突
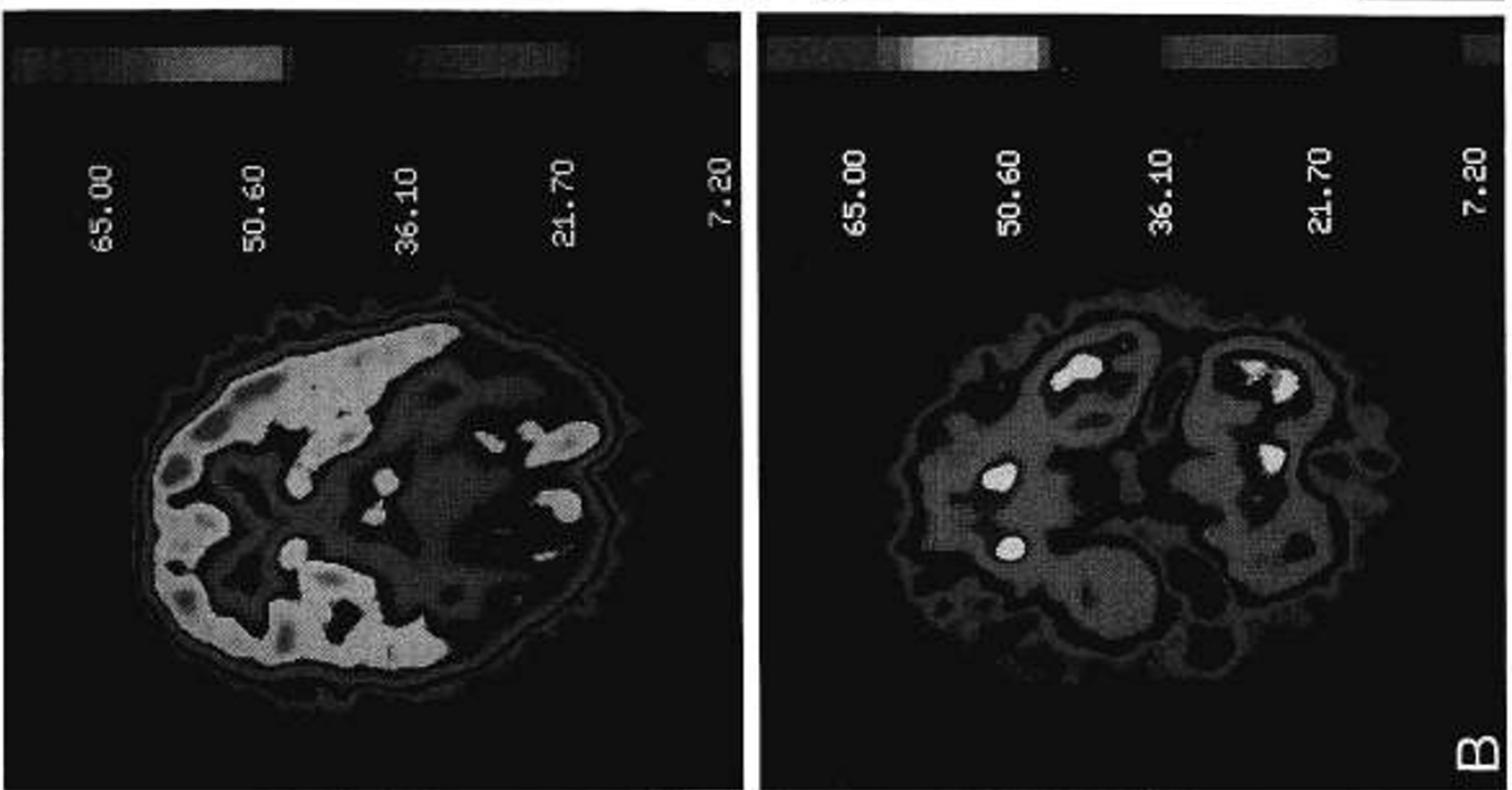

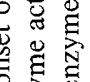

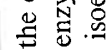

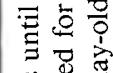

焉离

至

要

of

的

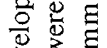

可

크을 군

记

突范

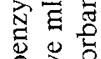

要这

a
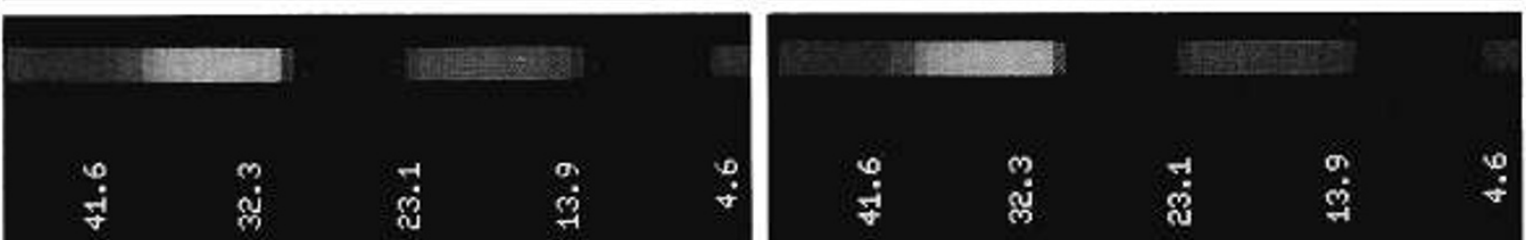

용

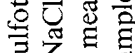

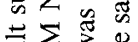

西思

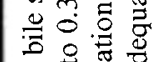

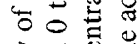

त $\sigma \overline{0}$
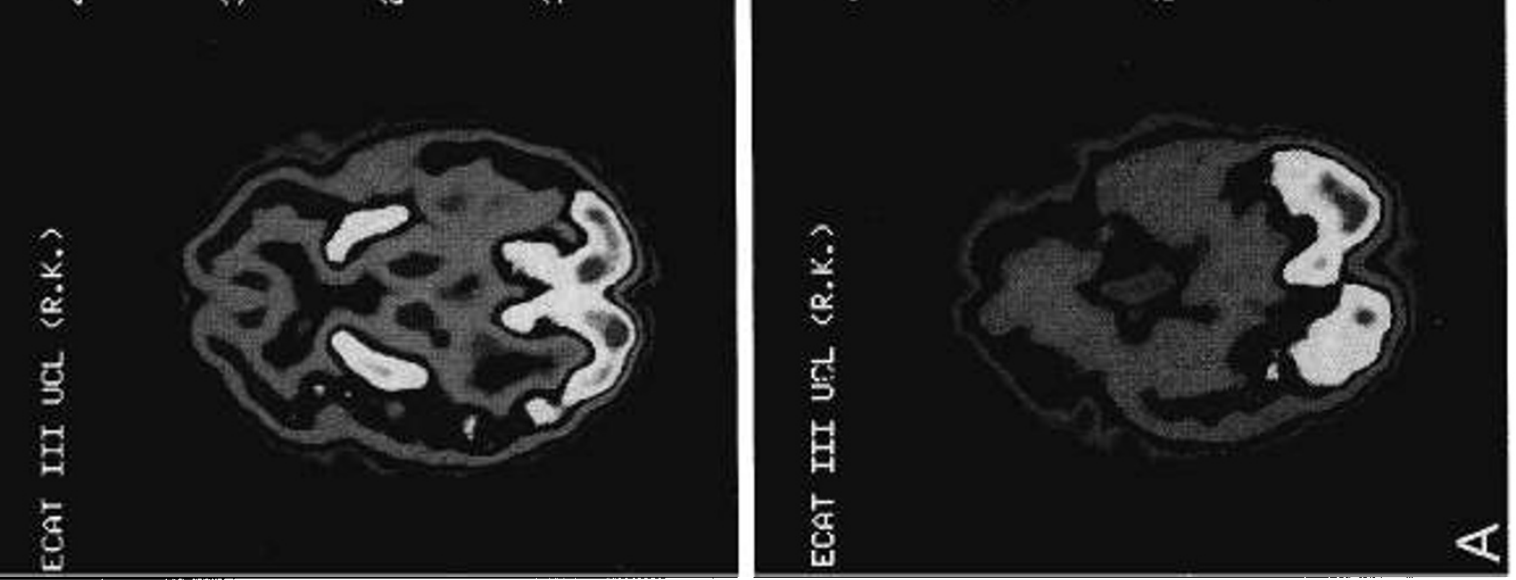

원

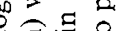

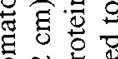

춘

×的

员言

$<=$

×

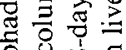

a

西

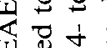

政:

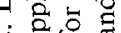

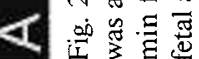


Table 1. Uptake of FDG in brain regions versus cerebellum of adenylosuccinase-deficient patients and controls*

\begin{tabular}{|c|c|c|c|c|c|c|}
\hline Region & Patient A & Patient B & Patient $\mathrm{C}$ & $\begin{array}{c}\text { "Normal" children } \\
(n=3) \\
(\text { mean } \pm \mathrm{SD})\end{array}$ & $\begin{array}{l}\text { Adult volunteers } \\
\quad(n=10) \\
(\text { mean } \pm \mathrm{SD}) \\
\end{array}$ & PKU \\
\hline 1. Right frontal cortex & 90.11 & 78.17 & 90.82 & $147.59 \pm 28.93$ & $132.57 \pm 13.83$ & 112.96 \\
\hline 2. Left frontal curtex & 94.85 & 78.43 & 92.41 & $153.18 \pm 24.83$ & $131.27 \pm 14.08$ & 117.37 \\
\hline 3. Right temporal cortex & 83.31 & 89.58 & 86.52 & $126.75 \pm 25.11$ & $113.45 \pm 12.01$ & 119.92 \\
\hline 4. Left temporal cortex & 91.56 & 90.50 & 91.35 & $135.35 \pm 15.10$ & $115.60 \pm 9.41$ & 124.73 \\
\hline 5. Right parietal cortex & 93.81 & 94.69 & 93.76 & $132.84 \pm 26.77$ & $112.20 \pm 11.88$ & 116.45 \\
\hline 6. Left parietal cortex & 90.72 & 97.86 & 93.47 & $131.45 \pm 24.84$ & $110.08 \pm 14.64$ & 119.95 \\
\hline 7. Right visual cortex & 108.55 & 114.12 & 105.94 & $144.05 \pm 19.87$ & $129.50 \pm 16.61$ & 136.08 \\
\hline 8. Left visual cortex & 107.79 & 114.15 & 106.12 & $144.98 \pm 18.69$ & $127.75 \pm 17.24$ & 142.48 \\
\hline 9. Right insula & 88.46 & 85.09 & 89.29 & $131.00 \pm 22.34$ & $117.57 \pm 9.68$ & 116.22 \\
\hline 10. Left insula & 88.80 & 85.42 & 92.94 & $130.85 \pm 17.68$ & $116.15 \pm 10.31$ & 122.30 \\
\hline 11. Right striatum & 98.11 & 111.71 & 101.29 & $128.71 \pm 8.01$ & $121.64 \pm 12.36$ & 133.73 \\
\hline 12. Left striatum & 96.98 & 106.10 & 105.36 & $129.18 \pm 7.03$ & $121.07 \pm 11.51$ & 143.28 \\
\hline 13. Right thalamus & 85.08 & 83.38 & 81.17 & $111.64 \pm 5.84$ & $115.19 \pm 9.12$ & 128.40 \\
\hline 14. Left thalamus & 35.43 & 83.34 & 83.81 & $113.41 \pm 2.91$ & $115.48 \pm 7.91$ & 131.56 \\
\hline 15. Right frontomesial cortex & 89.71 & 67.58 & 86.82 & $143.02 \pm 19.50$ & $129.88 \pm 10.65$ & 115.68 \\
\hline 16. Left frontomesial cortex & 86.54 & 68.21 & 86.93 & $146.64 \pm 18.81$ & $128.72 \pm 11.01$ & 117.23 \\
\hline Gray matter right hemisphere & 91.97 & 89.48 & 91.70 & $137.65 \pm 25.32$ & $120.60 \pm 10.27$ & 124.59 \\
\hline Gray matter left hemisphere & 92.06 & 89.25 & 92.70 & $139.76 \pm 19.59$ & $119.43 \pm 10.52$ & 129.35 \\
\hline
\end{tabular}

* Values are expressed in percent of FDG uptake in the cerebellum, which is little affected (see Table 2). Note: for each region patients A, B, and $\mathrm{C}$ differ significantly from normal children $(p<0.05$ in Student's $t$ test).

Table 2. Brain glucose utilization in patient $B$ and controls*

\begin{tabular}{lcccc}
\hline \multicolumn{1}{c}{ Brain regions } & Normal children & (n=3) & $\begin{array}{c}\text { Adult volunteers } \\
(n=10) \\
(\text { mean } \pm \text { SD) }\end{array}$ & PKU \\
\hline 1. Right frontal cortex & Patient B & $61.39 \pm 6.97$ & $44.48 \pm 9.27$ & 39.41 \\
2. Left frontal cortex & 23.70 & $63.91 \pm 6.89$ & $44.27 \pm 10.37$ & 40.95 \\
3. Right temporal cortex & 23.78 & $52.55 \pm 4.13$ & $38.24 \pm 8.86$ & 41.84 \\
4. Left temporal cortex & 27.16 & $57.04 \pm 9.59$ & $39.18 \pm 9.81$ & 43.52 \\
5. Right parietal cortex & 27.44 & $55.20 \pm 6.17$ & $37.90 \pm 9.20$ & 40.63 \\
6. Left parietal cortex & 28.71 & $54.80 \pm 7.07$ & $37.21 \pm 9.41$ & 41.85 \\
7. Right visual cortex & 29.67 & $60.32 \pm 7.55$ & $43.40 \pm 9.19$ & 47.48 \\
8. Left visual cortex & 34.60 & $60.80 \pm 8.06$ & $42.80 \pm 9.11$ & 49.71 \\
9. Right insula & 34.61 & $54.69 \pm 6.80$ & $39.87 \pm 10.11$ & 40.55 \\
10. Left insula & 25.80 & $54.91 \pm 7.90$ & $39.57 \pm 10.92$ & 42.67 \\
11. Right striatum & 25.90 & $55.02 \pm 13.66$ & $41.29 \pm 10.86$ & 46.66 \\
12. Left striatum & 33.87 & $55.04 \pm 12.52$ & $41.19 \pm 11.15$ & 49.99 \\
13. Right thalamus & 32.17 & $47.63 \pm 11.31$ & $38.84 \pm 8.78$ & 44.80 \\
14. Left thalamus & 25.28 & $48.54 \pm 12.32$ & $38.97 \pm 8.91$ & 45.90 \\
15. Right frontomesial cortex & 25.27 & $60.00 \pm 8.60$ & $43.97 \pm 10.90$ & 40.36 \\
16. Left frontomesial cortex & 20.49 & $61.70 \pm 10.22$ & $43.46 \pm 10.16$ & 40.90 \\
17. Right cerebellum & 20.68 & $41.60 \pm 10.90$ & $34.21 \pm 9.27$ & 33.30 \\
18. Left cerebellum & 30.46 & $42.30 \pm 9.20$ & $34.13 \pm 9.90$ & 36.48 \\
Gray matter right hemisphere & 30.17 & $57.30 \pm 6.16$ & $40.66 \pm 9.26$ & 43.47 \\
Gray matter left hemisphere & 27.06 & $58.57 \pm 8.00$ & $40.38 \pm 9.70$ & 45.13 \\
\hline
\end{tabular}

* Values shown are $\mu \mathrm{mol} /(100 \mathrm{~g} \cdot \mathrm{min}) \pm \mathrm{SD}$.

adenylosuccinase, and AMP deaminase; 4) a direct toxic effect of extracellular SAICAriboside and S-adenosine, the normally undetectable dephosphorylated derivatives of the substrates of adenylosuccinase. Owing to their structural resemblance with adenosine, a putative neuromodulator $(9,10)$, this toxicity may involve an interference with both receptors and uptake sites for adenosine.

Our study suggests that the latter mechanism does not account for the symptoms of adenylosuccinase deficiency. Indeed, the regional pattern of the impairment of the uptake of FDG in the patients does not correspond to the regional distribution of adenosine A1 receptors (11) and of adenosine uptake sites (12). This conclusion is corroborated by studies (13) that have failed to show an interference of SAICAriboside and S-adenosine with the binding and uptake of adenosine in crude membranes of rat brain cortex.
The observation that the alterations of FDG uptake in PKU tended to parallel those seen in adenylosuccinase deficiency is not unexpected. Metabolic disorders provoking psychomotor retardation would indeed be anticipated to affect the cerebral cortex more strongly, whereas basal ganglia and cerebellum would be less vulnerable. That the alterations observed are not entirely devoid of specificity, is evidenced by the recording of different patterns in other metabolic brain disorders such as HPRT deficiency with neurologic disease in which decreased glucose metabolic rates were recorded in the basal ganglia (14), where the activity of HPRT is normally highest within the human brain (15).

\section{REFERENCES}

1. Jaeken J, Van den Berghe G 1984 An infantile autistic syndrome characterized by the presence of succinyl purines in body fluids. Lancet 2:1058-1061 
2. Van den Berghe G, Jaeken J 1986 Adenylosuccinase deficiency. Adv Exp Med Biol 195A:27-33

3. Mazziotta JC, Phelps ME 1986 Positron emission tomography studies of the brain. In: Phelps ME, Mazziotta JC, Schelbert HR (eds) Positron Emission Tomography and Autoradiography: Principles and Applications for the Brain and Heart. Raven Press, New York, pp 493-580

4. Jaeken J, Wadman SK, Duran M, van Sprang FJ, Beemer FA, Holl RA, Theunissen PM, De Cock P, Van den Bergh F, Vincent MF, Van den Berghe G 1988 Adenylosuccinase deficiency: an inborn error or purine nucleotide synthesis. Eur J Pediatr (in press)

5. Hoffman EJ, Phelps ME, Huang SC, Collard PE, Bidaut LM, Schwab RL, Ricci AR 1986 Dynamic, gated and high resolution imaging with the ECAT III. IEEE Trans Nucl Sci 33:452-455

6. Phelps ME, Huang SC, Hoffman EJ, Selin C, Sokoloff L, Kuhl DE 1979 Tomographic measurement of local cerebral glucose metabolic rate in humans with [F-18]2-Fluoro-2-deoxy-D-glucose: validation of method. Ann Neurol 6:371-388

7. Kamo H, McGeer PL, Harrop R, McGeer EG, Calne DB, Martin WRW, Pate BD 1987 Positron emission tomography and histopathology in Pick's disease. Neurology 37:439-445

8. Lowenstein JM 1972 Ammonia production in muscle and other tissues: the purine nucleotide cycle. Physiol Rev 52:382-414

9. Snyder SH 1985 Adenosine as a neuromodulator. Ann Rev Neurosci 8:103 124

10. Stiles GL 1986 Adenosine receptors: structure, function and regulation. Trends Pharmacol Sci 7:486-490

11. Goodman RR, Snyder SH 1982 Autoradiographic localization of adenosine receptors in rat brain using $\left[{ }^{3} \mathrm{H}\right]$ cyclohexyladenosine. J Neurosci $2: 1230$ 1241

12. Bisserbe JC, Patel J, Marangos PJ 1985 Autoradiographic localization of adenosine uptake sites in rat brain using $\left[{ }^{3} \mathrm{H}\right]$ nitrobenzylthioinosine. J Neurosci 5:544-550

13. Vincent MF, Van den Berghe G 1988 Influence of succinylpurines on the binding of adenosine to a particulate fraction of rat cerebral cortex. Pediatr Res (in press)

14. Palella TD, Hichwa RD, Ehrenkaufer RL, Rothley JM, McQuillan MA, Young AB, Kelley WN 1985 18F-fluorodeoxyglucose PET scanning in HPRT deficiency. Am J Hum Genet 37:A70

15. Rosenbloom FM, Kelley WN, Miller J, Henderson JF, Seegmiller JE 1967 Inherited disorders of purine metabolism: correlation between central nervous system dysfunction and biochemical defects. JAMA 202:175-181 